\title{
CEREBRAL EVOKED RESPONSES IN HYPOTHYROIDISM ${ }^{1,2}$
}

\author{
H. Nishitani, M.D. ${ }^{3}$ And K. A. KooI, M.D. \\ Laboratory of Electroencephalography, Neuropsychiatric Institute, University of Michigan Medical Center, \\ Ann Arbor, Mich. 48104 (U.S.A.)
}

(Accepted for publication: September 18, 1967)

\section{INTRODUCTION}

The profound influence of the thyroid gland upon brain function is well known clinically. A deficiency of thyroid hormone produces such psychic symptoms as lack of concentration, slow mentation, impairment of memory, lethargy and, rarely, delirium and coma. Electroencephalographically, characteristic changes are slowing of the dominant rhythm, reduction of its amplitude and reduced photic driving (Bertrand $e t$ al. 1938; Ross and Schwab 1939; Browning et al. 1954; Lansing and Trunnell 1963; Miyake et al. 1964). The rhythmic after-discharge to slowly repeated flashes may also be poorly developed (Barlow 1967).

This study assesses possible effects of the thyroid deficiency state upon visually evoked responses of the brain by the averaging technique. In addition, simple motor reaction time is examined in relation to characteristics of the cerebral evoked response during the hypothyroid state and following institution of replacement therapy.

\section{SUBJECTS AND METHOD}

\section{Subjects}

Forty-five ( 35 female and 10 male) patients with hypothyroidism were selected from the Nuclear Med:cine Unit of the University of Michigan Medical Center. The subjects were all

1 This investigation was supported in part by U.S. Public Health Service Grant NB 02560.

2 Portions of this paper were presented at the 1965 Annual Meeting of the American EEG Society (see this Journal, 1966, 21: 406).

${ }^{3}$ Fulbright Research Fellow. Present address: Department of Medicine, Kyoto University Medical School, Kyoto (Japan). volunteers, had proven hypothyroidism and were free from other diseases that might produce central nervous system disorder. Their ages ranged from 15 to 61 years (average, 35.3 years). Fortyone patients had been totally thyroidectomized surgically because of malignant thyroid tumor. During the follow-up period, some of them were also treated with high doses of ${ }^{131} \mathrm{I}$. The period after thyroidectomy ranged from 2 months to 19 years, averaging 3.6 years, during which time they were on maintenance doses of desiccated thyroid. The other four cases had hypothyroidism which was idiopathic or secondary to a degenerative disorder, the duration of illness being 4-25 years. All forty-five cases were sent to the EEG Laboratory 6 weeks after replacement therapy was discontinued. Thus, the patient group consisted largely of cases with temporary and usually mild hypothyroidism. Twenty patients who agreed to have a follow-up study had a second examination after 8 weeks replacement therapy with desiccated thyroid.

A control group was composed of forty-five (35 female, 10 male) normal adults without any neurological or endocrinological disorders. Their average age was 34.5 years, ranging from 14 to 64 years.

\section{Procedures}

An 8-channel Grass Model III electroencephalograph was employed for EEG recording and to provide pre-amplification of signals processed by 2 computers of average transients(CAT). The frequency response of the system, selected for optimal rejection of myogenic potentials, was such that output amplitude was down $40 \%$ and $80 \%$ at $50 \mathrm{c} / \mathrm{sec}$ and $100 \mathrm{c} / \mathrm{sec}$ respectively (see Kooi and Bagchi 1964a). The scalp electrode

Electroenceph. clin. Neurophysiol., 1968, 24 : 554-560 
placements were bilateral frontal, central, temporal and occipital. An infraorbital lead was placed on the inferior margin of the orbit of the eye corresponding to the dominant cerebral hemisphere in respect to handedness. A posterior mid-cervical lead, placed $3 \mathrm{~cm}$ below the inion was used to monitor cervical photomyoclonic responses. All leads were paired with combined ear reference. The subjects sat in a comfortable chair in a dark, quiet room with their eyes open. Background light intensity was adjusted to be 1 foot-candle at the subjects' eyes. After a $4 \mathrm{~min}$ routine EEG tracing, a Grass PS-2 photic stimulator lamp was placed $5 \mathrm{~cm}$ before their eyes. The lamp was fitted with an opal glass face which improved diffusion and reduced the light intensity by $20 \%$ from the basic rating of 200,000 peak candles. A soundproof encasement eliminated awareness of the sound which accompanies each flash. Flashes were presented at random once every $4-6 \mathrm{sec}$. The CAT, triggered by the light flashes, summated the evoked responses on-line, the resultant display being photographed by a Hathaway oscilloscope camera.

Four series of 50 summations of the response were carried out, analysis times being alternately $250 \mathrm{msec}$ and $500 \mathrm{msec}$. In the third and fourth series, the patients were instructed to press a push button as soon as possible after perception of the flash. Closure of a simple battery-operated circuit provided a pulse that was reshaped by a Mnemotron amplitude discriminator(Model 605) to be stored as a count in the appropriate address of one of the CATs being operated to furnish a reaction time histogram. Analysis time was $4 \mathrm{sec}$ and class interval $10 \mathrm{msec}$. The mode was used as a representative value of the reaction time. Simultaneously, the evoked responses from 4 regions of the dominant hemisphere were summated by a second CAT. The EEG was recorded throughout the examination.

The evoked responses formally analyzed were those derived from occipital and central regions of the dominant hemisphere. Amplitudes of individual waves were measured between the peak (or trough) of the wave and the trough (or peak) of the preceding wave. Latencies were measured to the peak of each of the waves scored.

The $t$ test was employed for the statistical evaluation of the differences between two means for each wave. Correlation coefficients between reaction time and mean latencies of evoked responses were computed.

\section{RESULTS}

\section{Evoked responses of untreated hypothyroid and control subjects}

Most of the hypothyroid patients showed alternating deflections similar to those described in normal adults (see Kooi and Bagchi 1964a); i.e., three negative peaks designated as I, III and $\mathrm{V}$ and two positive troughs designated as II and IV, both in occipital (O) and central (C) regions. Typical curves are shown in Fig. 1.

Means of the latencies and amplitudes of responses for the occipital and central regions in forty-five control subjects and forty-five patients with hypothyroidism are shown in Tables I and II. Differences between the two groups are presented in the column " $\mathrm{H}$ minus C".

Means of the latencies of all deflections from OI through OV were greater in the hypothyroid group compared with corresponding waves in the control group. The $t$ test showed that the differences for waves OII, OIII and OIV were significant at the $0.1 \%$ level of confidence. The amplitudes of the occipital waves tended to be smaller in the hypothyroid group as compared to the

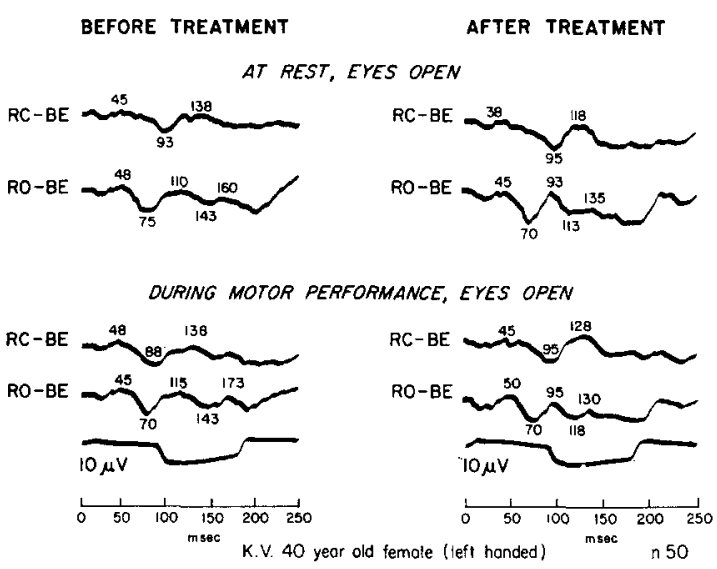

Fig. 1

Effect of motor performance upon visually evoked potentials recorded from central and occipital regions in a representative patient before and after being placed on desiccated thyroid. An upward deflection means relative negativity at the scalp electrode. Samples traced from direct photographs of oscilloscopic displays. $\mathrm{C}=$ central; $\mathrm{O}=$ occipital; $\mathrm{BE}=$ both ears; $\mathrm{R}=$ right $; \mathrm{n} 50=$ average of 50 responses.

Electroenceph. clin. Neurophysiol., 1968, 24 : 554-560 
TABLE I

Mean latencies and amplitudes of occipital responses in control, hypothyroid and treated groups

\begin{tabular}{|c|c|c|c|c|c|c|c|}
\hline & \multirow{2}{*}{$\begin{array}{l}\text { Control } \\
\text { (C) }\end{array}$} & \multirow{2}{*}{$\begin{array}{l}\text { Hypothyroid } \\
\text { (H) }\end{array}$} & \multirow{2}{*}{$\begin{array}{l}\text { Follow-up } \\
\text { untreated } \\
\left(\mathrm{H}^{\prime}\right)\end{array}$} & \multirow{2}{*}{$\begin{array}{c}\text { Follow-up } \\
\text { treated } \\
\left(\mathbf{H}^{\prime} \mathbf{t}\right)\end{array}$} & \multicolumn{3}{|c|}{ Differences between groups } \\
\hline & & & & & $\mathrm{H}-\mathrm{C}$ & $H^{\prime}-H^{\prime} t$ & $\mathrm{H}^{\prime} \mathrm{t}-\mathrm{C}$ \\
\hline$n$ & 45 & 45 & 20 & 20 & & & \\
\hline \multicolumn{8}{|c|}{ Latency (msec) } \\
\hline OI & 52.3 & 54.6 & 52.0 & 51.8 & 2.3 & 0.2 & -0.5 \\
\hline OII & 75.7 & 86.4 & 86.3 & 81.0 & $10.7 \dagger$ & $5.3^{* * *}$ & 5.3 \\
\hline OIII & 92.4 & 102.8 & 103.7 & 97.4 & $10.4 \dagger$ & $8.3^{* * *}$ & 5.0 \\
\hline OIV & 111.7 & 121.8 & 122.7 & 113.6 & $10.1 \dagger$ & $9.1^{* *}$ & 1.9 \\
\hline OV & 143.5 & 148.8 & 148.1 & 137.4 & 5.3 & $10.7^{* * *}$ & -8.1 \\
\hline \multicolumn{8}{|c|}{ Amplitude $(\mu \mathrm{V})$} \\
\hline OI & 3.9 & 3.7 & 3.5 & 3.5 & -0.2 & 0.0 & -0.4 \\
\hline OII & 6.5 & 8.7 & 8.8 & 9.8 & $2.2^{*}$ & -1.0 & 3.3 \\
\hline OIII & 5.8 & 4.3 & 5.0 & 6.8 & -1.5 & -1.8 & 1.0 \\
\hline OIV & 7.0 & 4.4 & 4.2 & 4.9 & $-2.6^{* *}$ & -0.7 & -2.1 \\
\hline ov & 7.8 & 7.6 & 7.5 & 7.8 & -0.2 & -0.3 & 0.0 \\
\hline
\end{tabular}

Levels of significance in this and subsequent Tables: ${ }^{*} P<0.05,{ }^{* *} P<0.02,{ }^{* * *} P<0.01$ and $\dagger P<0.001$.

TABLE II

Mean latencies and amplitudes of central responses in control, hypothyroid and treated groups

\begin{tabular}{|c|c|c|c|c|c|c|c|}
\hline & \multirow{2}{*}{$\begin{array}{l}\text { Control } \\
\text { (C) }\end{array}$} & \multirow{2}{*}{$\begin{array}{l}\text { Hypothyroid } \\
\text { (H) }\end{array}$} & \multirow{2}{*}{$\begin{array}{l}\text { Follow-up, } \\
\text { untreated } \\
\left(\mathbf{H}^{\prime}\right)\end{array}$} & \multirow{2}{*}{$\begin{array}{c}\text { Follow-up, } \\
\text { treated } \\
\left(\mathrm{H}^{\prime} \mathrm{t}\right)\end{array}$} & \multicolumn{3}{|c|}{ Differences between groups } \\
\hline & & & & & $\mathrm{H}-\mathrm{C}$ & $H^{\prime}-H^{\prime} t$ & $\mathrm{H}^{\prime} \mathrm{t}-\mathrm{C}$ \\
\hline$n$ & 45 & 45 & 20 & 20 & & & \\
\hline \multicolumn{8}{|c|}{ Latency (msec) } \\
\hline CI & 49.7 & 50.7 & 51.5 & 51.1 & 1.0 & 0.4 & 1.4 \\
\hline CII & 74.7 & 78.2 & 79.6 & 80.5 & 3.5 & -0.9 & 5.8 \\
\hline CIII & 89.3 & 93.0 & 96.2 & 89.2 & 3.7 & $7.0^{* *}$ & -0.1 \\
\hline CIV & 104.7 & 107.2 & 108.3 & 105.1 & 2.5 & 3.2 & 0.4 \\
\hline $\mathrm{CV}$ & 134.6 & 140.8 & 139.6 & 133.8 & $6.2^{*}$ & $5.8^{* *}$ & -0.8 \\
\hline \multicolumn{8}{|c|}{ Amplitude $(\mu \mathrm{V})$} \\
\hline CI & 4.1 & 3.3 & 3.2 & 3.2 & $-0.8^{*}$ & 0.0 & -0.9 \\
\hline CII & 6.8 & 5.3 & 5.5 & 6.1 & -1.5 & -0.6 & -0.7 \\
\hline CIII & 3.7 & 3.2 & 3.3 & 3.6 & -0.5 & -0.3 & -0.1 \\
\hline CIV & 4.7 & 3.7 & 4.1 & 5.8 & -1.0 & $-1.7^{* *}$ & 1.1 \\
\hline $\mathrm{CV}$ & 9.6 & 8.0 & 7.9 & 11.2 & -1.6 & $-3.3^{* * *}$ & 1.6 \\
\hline
\end{tabular}

control group but only that of OIV was significantly different. The amplitude of OII was significantly greater in the patient group.

For the central region, all 5 components in the hypothyroid group had longer mean latencies than the corresponding waves in the control group, although only the difference for $\mathrm{CV}$ was statistically significant. There was a tendency for central waves to have smaller amplitudes than those of the normal subjects.

II. Evoked responses of patients before and after replacement therapy

The latencies and amplitudes of the occipital and central waves in twenty hypothyroid patients before and after replacement therapy are tabu- 
lated in Tables I and II; these also show the differences between means for the two groups. In the occipital region, the latencies of all waves except OI decreased significantly after treatment but the mean amplitudes were not substantially changed. For the central data, the analysis showed that latencies of CIII and CV decreased and amplitudes of CIV and CV increased significantly after thyroid medication had been instituted. Fig. 1 illustrates these changes.

There were no significant differences between the forty-five patients before treatment $(\mathrm{H})$, and the twenty untreated hypothyroid cases $\left(\mathrm{H}^{\prime}\right)$ selected from the whole group for follow-up.

TABLE III

Mean latencies and amplitudes of occipital responses without and with motor performance in patients before and after treatment

\begin{tabular}{|c|c|c|c|c|c|c|}
\hline & \multicolumn{3}{|c|}{ Hypothyroid untreated $(n=34)$} & \multicolumn{3}{|c|}{ Hypothyroid treated $(n=16)$} \\
\hline & $\begin{array}{l}\text { Without } \\
\text { motor } \\
\text { performance }\end{array}$ & $\begin{array}{c}\text { With } \\
\text { motor } \\
\text { performance }\end{array}$ & $\begin{array}{l}\text { Differences } \\
\text { of the } \\
\text { groups }\end{array}$ & $\begin{array}{l}\text { Without } \\
\text { motor } \\
\text { performance }\end{array}$ & $\begin{array}{l}\text { With } \\
\text { motor } \\
\text { performance }\end{array}$ & $\begin{array}{l}\text { Differences } \\
\text { of the } \\
\text { groups }\end{array}$ \\
\hline \multicolumn{7}{|c|}{ Latency (msec) } \\
\hline OI & 53.5 & 51.5 & 2.0 & 50.5 & 48.4 & 2.1 \\
\hline OII & 86.6 & 81.0 & $5.6^{* * * *}$ & 77.2 & 74.2 & 3.0 \\
\hline OIII & 102.4 & 99.5 & 2.9 & 96.3 & 92.5 & 3.8 \\
\hline OIV & 120.2 & 119.1 & 1.1 & 114.8 & 112.2 & 2.6 \\
\hline ov & 148.2 & 144.0 & 4.2 & 139.1 & 138.7 & 0.4 \\
\hline \multicolumn{7}{|c|}{ Amplitude $(\mu \mathrm{V})$} \\
\hline OI & 3.6 & 3.5 & 0.1 & 3.1 & 3.9 & -0.8 \\
\hline OII & 8.8 & 7.5 & 1.3 & 7.1 & 7.3 & -0.2 \\
\hline OIII & 4.2 & 4.2 & 0.0 & 6.3 & 4.5 & 1.8 \\
\hline OIV & 4.6 & 5.1 & -0.5 & 6.5 & 7.5 & -1.0 \\
\hline ov & 8.1 & 7.1 & $1.0^{*}$ & 7.7 & 8.2 & -0.5 \\
\hline
\end{tabular}

TABLE IV

Mean latencies and amplitudes of central responses without and with motor performance in patients before and after treatment

\begin{tabular}{|c|c|c|c|c|c|c|}
\hline & \multicolumn{3}{|c|}{ Untreated hypothyroid $(n=34)$} & \multicolumn{3}{|c|}{ Treated hypothyroid $(n=16)$} \\
\hline & $\begin{array}{l}\text { Without } \\
\text { motor } \\
\text { performance }\end{array}$ & $\begin{array}{c}\text { With } \\
\text { motor } \\
\text { performance }\end{array}$ & $\begin{array}{l}\text { Differences } \\
\text { between the } \\
\text { groups }\end{array}$ & $\begin{array}{c}\text { Without } \\
\text { motor } \\
\text { performance }\end{array}$ & $\begin{array}{l}\text { With } \\
\text { motor } \\
\text { performance }\end{array}$ & $\begin{array}{c}\text { Differences } \\
\text { between the } \\
\text { groups }\end{array}$ \\
\hline \multicolumn{7}{|c|}{ Latency (msec) } \\
\hline CI & 52.7 & 52.7 & 0.0 & 50.7 & 50.3 & 0.4 \\
\hline CII & 80.6 & 81.0 & -0.4 & 81.0 & 82.0 & -1.0 \\
\hline CIII & 96.1 & 96.1 & 0.0 & 88.3 & 90.6 & -2.3 \\
\hline CIV & 108.5 & 108.8 & -0.3 & 105.0 & 104.3 & 0.7 \\
\hline $\mathrm{CV}$ & 144.0 & 143.8 & 0.2 & 133.6 & 136.1 & -2.5 \\
\hline \multicolumn{7}{|c|}{ Amplitude $(\mu \mathrm{V})$} \\
\hline $\mathrm{CI}$ & 3.5 & 3.8 & -0.3 & 3.6 & 4.0 & -0.4 \\
\hline CII & 5.9 & 6.5 & -0.6 & 5.9 & 6.9 & -1.0 \\
\hline CIII & 3.4 & 4.1 & -0.7 & 3.4 & 3.5 & -0.1 \\
\hline CIV & 3.7 & 4.0 & -0.3 & 6.3 & 7.5 & -1.2 \\
\hline $\mathrm{CV}$ & 8.7 & 10.5 & $-1.8^{*}$ & 11.1 & 13.9 & $-2.8^{* * *}$ \\
\hline
\end{tabular}


III. Evoked responses of treated hypothyroid and control groups

The differences between the means of measurements for twenty cases with treated hypothyroidism and forty-five control subjects are shown in Tables I and II. Many of the measurements of the H't group approached closely those of the control group although exceptions were encountered, particularly, in terms of amplitude. There were no significant group differences.

\section{Reaction times of patients before and after replacement therapy}

In thirty-four of the forty-five hypothyroid patients, reaction times were measured. Mean reaction times and standard deviations for the untreated hypothyroid patients and twenty treated patients were $266 \pm 46 \mathrm{msec}$ and $233 \pm 20$ msec respectively. The means were significantly different $(P<0.001)$.

\section{Evoked responses in patients with and without motor performance}

Tables III and IV show mean latencies and amplitudes of occipital and central evoked responses in thirty-four untreated and sixteen treated patients at rest and during the reaction time experiments. The $t$ test for paired observations showed only the differences in the latency of OII and the amplitude of $\mathrm{CV}$ to be significant. Amplitudes of occipital waves and latencies of cen-

\section{TABLE V}

Correlations of reaction times with latencies and amplitudes of evoked responses

\begin{tabular}{lrrrrr}
\hline & $\begin{array}{c}\text { Untreated hypothy- } \\
\text { roid }(n=34)\end{array}$ & & $\begin{array}{r}\text { Treated } \\
(n=16)\end{array}$ \\
\cline { 2 - 3 } & Latency & Amplitude & & Latency & Amplitude \\
\hline CI & 0.02 & 0.00 & & 0.27 & 0.19 \\
CII & -0.05 & 0.04 & & -0.31 & 0.11 \\
CIII & 0.07 & $0.44^{* * *}$ & & 0.12 & 0.25 \\
CIV & 0.14 & 0.04 & & 0.12 & -0.09 \\
CV & -0.12 & 0.06 & & $0.53^{*}$ & 0.14 \\
& & & & & \\
OI & $0.39^{*}$ & $0.42^{* *}$ & & -0.12 & 0.19 \\
OII & 0.29 & 0.20 & & -0.13 & -0.31 \\
OIII & 0.11 & 0.02 & & 0.13 & -0.17 \\
OIV & 0.02 & -0.04 & & 0.22 & 0.24 \\
OV & -0.06 & 0.14 & & 0.34 & 0.15 \\
\hline
\end{tabular}

tral waves changed minimally except for a significantly decreased amplitude of $\mathrm{OV}$.

For the treated group, the over-all tendency was the same as that in the untreated group. The increase in the amplitude of $\mathrm{CV}$ during motor performance was more marked after medication than before medication while the change of latency of OII lost statistical significance. Representative response curves are found in Fig. 1.

\section{Latencies and amplitudes of evoked responses and average reaction times (Table $\mathrm{V}$ )}

In untreated patients, both latency and amplitude of OI correlated positively with reaction time. The correlation with the amplitude of CIII was also significant. None of these correlations reached significance in the treated group while a new positive correlation emerged, that of the latency of $\mathrm{CV}$ with reaction time.

\section{DISCUSSION}

In patients with temporary and generally mild hypothyroidism, we identified 5 major deflections of photically induced cerebral responses in occipital and central regions similar to those of normal subjects. However, peak latencies of the various waves were frequently longer and their amplitudes smaller compared with those of ageand sex-matched normal subjects. After a short period of hormone therapy, most components of the patients' responses showed a tendency for latencies to decrease and amplitudes to increase. The data of the present study suggest that the effects of temporary lack of thyroid hormone on photically induced responses of the adult are largely, if not fully reversible, there being no significant differences between latencies and amplitudes of corresponding waves of normal subjects and treated patients.

The studies of Bradley et al. (1961) in cretin rats appear to be in general accord with these observations. These authors postulated that the change in latency was due to reversible metabolic factors while the small amplitude reflected irreversible anatomical changes which occurred at an early stage of cerebral development. They observed significant changes only in the latency, not in the amplitude, of the recruiting response following thyroidectomy during adult life. Possibly divergent results are those of Short et al. (1964) who,

Electroenceph. clin. Neurophysiol., 1968, 24 : 554-560 
in acute experiments in cats, observed increase of the latency of the secondary evoked response to sciatic nerve stimulation after administration of triiodothyronine. Amplitude was increased.

Whereas it is reasonable to ascribe, at least in part, the shortened latencies after treatment to an increase in cerebral metabolic rate, this explanation is less obviously satisfying for the observed differences in wave amplitudes. The latter changes may be more directly related to level of alertness (see Jouvet 1957; Hernández Peón and Donoso 1959; García-Austt et al. 1964). The greater average amplitude of $\mathrm{CV}$ during the motor reaction time experiments as compared with the resting studies is fully in accord with this relationship. In addition, the difference in amplitude of this same wave between treated and untreated patients, smaller in the latter group, is also compatible with this line of reasoning. A noteworthy exception appearing in our data from untreated patients is the difference in the average amplitude of $\mathrm{OV}$ between the motor task and resting conditions, this wave becoming smaller rather than larger. This tendency is readily explained, however, if one considers this wave to be a timelocked alpha wave, a concept supported by several lines of evidence (Kooi and Bagchi 1964b; Kooi et al. 1965). Its reduction in amplitude parallels that of the alpha rhythm under conditions of high visual attentiveness.

Significant positive correlations were found between the patients' reaction times and several aspects of the cerebral evoked responses. Of special interest were the correlations with OI in the untreated patients. This early surface negative component might be expected to be the wave most likely to reflect dysfunction of the retina and visual pathway secondary to the hypothyroid state. Pearlman and Burian (1964) have shown that hypothyroidism may lead to changes in the electrical activity of the retina, lending credence to the possible importance of effects occurring at the receptor level. Insofar as the correlation with latency is concerned, it can be concluded that delayed reaction time in patients with hypothyroidism may be in part attributable to a retardation of peripheral or central processes occurring within $\mathbf{4 0} \mathrm{msec}$ after the test signal. Such a correlation was not evident in our treated patients nor in the normal subjects studied by Dustman and Beck (1965). The meaning of the other significant positive correlations with reaction time, that of the amplitude of CIII in the untreated patients, and the latency of $\mathrm{CV}$ in the treated patients, is unknown at this time. They were not unanticipated, however, in view of the description by Gilden et al. (1966) of potentials recordable from the scalp overlying the motor region which precede voluntary movement and are timerelated to it.

\section{SUMMARY}

Cerebral evoked responses to light have been studied in forty-five patients with hypothyroidism and forty-five normal subjects matched for age and sex. Average latencies of all waves examined were longer for the patient sample, some of the differences being highly significant on statistical testing. With one exception, average amplitudes of the waves were smaller in patients with hypothyroidism as compared with normal subjects. The lone exception was the second occipital wave, surface positive, which had a significantly larger amplitude.

Replacement therapy resulted in normalization of cerebral responses, no significant differences being found between treated patients and controls.

Evoked responses obtained from patients at rest and during a reaction time task were different in several respects. The findings were discussed in relation to the effect of level of attention upon electrocortical activity.

The authors wish to express their appreciation to Dr. W. H. Beierwaltes and Dr. J. C. Sisson for referring patients for study. The technical assistance of Mr. W. Kohl and Mrs. D. Chiao is also gratefully acknowledged. Appreciation is extended to Miss E. Schaeffer of The University of Michigan Statistical Research Laboratory for statistical assistance.

\section{REFERENCES}

BARLOw, J. S. Intrinsic and induced EEG rhythms in severe hypothyroidism secondary to panhypopituitarism. A case report. Electroenceph. clin. Neurophysiol., 1967, 22: 266-269.

Bertrand, I., Delay, J. et Guillain, J. L'électroencéphalogramme dans le myxoedème. $C$. R. Soc. Biol. (Paris), 1938, 129: 395-398.

Bradley, P. B., Eayrs, J. T., Glass, A. and Heath, R. $W$. The maturational and metabolic consequences of neonatal thyroidectomy upon the recruiting response in the rat. Electroenceph. clin. Neurophysiol., 1961, 13: $577-586$.

Electroenceph. clin. Neurophysiol., 1968, 24 : 554-560 
Browning, T. B., Atrins, R. W. and Weiner, H. Cerebral metabolic disturbances in hypothyroidism: Clinical and electroencephalographic studies of the psychosis of myxedema and hypothyroidism. Arch. intern. Med. (Chic.), 1954, 93: 938-950.

Dustman, R. E. and Beck, E. C. Phase of alpha brain waves, reaction time and visually evoked potentials. Electroenceph. clin. Neurophysiol., 1965, 18: 433-440.

García-Austr, E., Bogacz, J. and Vanzulli, A. Effects of attention and inattention upon visual evoked response. Electroenceph. clin. Neurophysiol., 1964, 17: 136-143.

Gilden, L., Vaughan JR., H. G. and Costa, L. D. Summated human EEG potentials with voluntary movement. Electroenceph. clin. Neurophysiol., 1966, 20: 433-438.

Hernández Peón, R. et Donoso, M. Activité sous-corticale du cerveau humain en état de veille évoquée par stimulation photique. First International Congress of Neurological Sciences. Brussels, 1957. Vol. III. Electroencephalography, clinical neurophysiology, and epilepsy. Pergamon, London, 1959: 385-396.

JOUVET, M. Étude neurophysiologique chez l'homme de quelques mécanismes sous corticaux de l'attention. Psychol. franc., 1957, 2: 254-260.

KooI, K. A. and BAGCHI, B. K. Visual evoked responses in man: normative data. In R. KaTzMan (Ed.), Sensory evoked responses in man. Ann. N. Y. Acad. Sci., 1964a, 112: 254-269.

Koor, K. A. and BAGCH, B. K. Observations on early components of the visual evoked response and occipital rhythms. Electroenceph. clin. Neurophysiol., 1964b, 17: 638-643.

KooI, K. A., GÜVener, A. M. and BAGCHI, B. K. Visual evoked responses in lesions of the higher optic pathways. Neurology (Minneap.), 1965, 15: 841-854.

LANSING, R. W. and TrunNell, J. B. Electroencephalographic changes accompanying thyroid deficiency in man. J. clin. Endocr., 1963, 23: 470-480.

MiYaKe, T., Nishitani, H. and Yamashiki, Y. Electroencephalogram in myxedema. Clin. Neurol. (Tokyo), 1964, 4: 608-610.

Pearlman, J. T. and Burian, H.M. Electroretinographic findings in thyroid dysfunction. Amer. J. Ophthal., 1964, 58: 216-226.

Ross, D. A. and SchwAB, R. S. The cortical alpha rhythm in thyroid disorders. Endocrinology, 1939, 25: 75-79.

ShorT, M. J., HeIN, P. and WILson, W.P. Thyroid hormone and brain function. III. Influence of triiodothyronine on evoked potentials of the cortex and reticular formation and upon the interrelationship of caudate and reticular activity of the cat. Electroenceph. clin. Neurophysiol., 1964, 17: 414-419.

Reference: Nishrtani, H. and Koor, K. A. Cerebral evoked responses in hypothyroidism. Electroenceph. clin. Neurophysiol., 1968, 24: 554-560. 